\title{
ANTIEPILEPTIC RECTAL HYDROGEL LOADED WITH CARBAMAZEPINE - RICE BRAN WAX MICROSPHERES
}

\author{
KRISHNAPRIYA M, KARTHIKA RAMESH, SREEJA C NAIR* \\ Department of Pharmaceutics, Amrita School of Pharmacy, Amrita Institute of Medical Sciences and Research Centre, Amrita Vishwa \\ Vidyapeetham, Amrita University, Kochi - 682 041, Kerala, India. Email: sreejacnair@aims.amrita.edu
}

Received: 12 November 2016, Revised and Accepted: 06 December 2016

\section{ABSTRACT}

Objectives: The objective behind the study is to develop a mucoadhesive rectal hydrogel from carbamazepine (CBZ) - rice bran wax (RBW) microspheres for the purpose of controlled release for the treatment of epilepsy.

Methods: The study was conducted to formulate controlled release rectal hydrogel loaded with CBZ - RBW microspheres in two different natural polymers, RBW and collagen which are prepared by modified cooling induced solidification method and gel preparation along with their evaluation studies

Results: A thorough analysis of the optimized gel revealed that all the evaluation parameters evaluated are within the acceptable limits. Further, the optimized microsphere formulation (M5) was used to formulate it as rectal hydrogel using polymer collagen and was characterized. The mucoadhesion time of $25 \% \mathrm{w} / \mathrm{w}$ collagen hydrogel (H4) was 565 minutes, allowing the loaded microspheres to be attached on rectal mucosa. In vitro drug release from the mucoadhesive hydrogel formulations showed controlled drug release pattern with a maximum drug release of $96.45 \pm 0.35 \%$ for optimized $\mathrm{H} 4$ formulation after $12 \mathrm{hr}$, followed zero order release pattern with diffusion mediated Higuchi model. Ex vivo permeation studies using bovine rectal mucosa revealed that $\mathrm{H} 4$ formulation showed greater permeability compared to control. Histopathological findings revealed that $\mathrm{H} 4$ formulation is safer for rectal administration without any signs of rectal irritancy. The stability studies of optimized formulation (H4) proved that hydrogel remained stable over a wide range of temperature condition.

Conclusion: Hence, the developed rectal hydrogel formulation seems to be a viable alternative to conventional drug delivery system for the effective management of epilepsy.

Keywords: Carbamazepine, Rice bran wax, Rectal hydrogel, Sustainability.

(C) 2017 The Authors. Published by Innovare Academic Sciences Pvt Ltd. This is an open access article under the CC BY license (http://creativecommons. org/licenses/by/4. 0/) DOI: http://dx.doi.org/10.22159/ajpcr.2017.v10i3.16144

\section{INTRODUCTION}

Epilepsy is a disorder of brain that is characterized by neuronal misfiring and send out incorrect signals, ultimately lead to seizures. Seizures can vary between brief loss of awareness, to mood swings, to loss of body function and motor control [1]. Pathophysiology of epilepsy is very complex. Pathophysiological mechanisms of some forms of epilepsy are partially understood [2].

Antiepileptic drugs (AEDs) are different group of pharmaceuticals used in the treatment of epileptic seizures. The major targets for the marketed AEDs are voltage-gated sodium channel and components of GABA system $\left(\mathrm{GABA}_{\mathrm{A}}\right.$ receptor, GAT-1 GABA transporter). Other considerable targets are voltage gated calcium channels, SV2A.For a long time, it was tried to develop a single drug for the treatment of all type of epilepsies. Specific choices of AED depend on the individual patient's condition and the particular side effects of the AED. None has emerged as being superior to either old standard or newer AED drugs [3-6]. The article mainly focused on the development and evaluation of rectal collagen hydrogel loaded with carbamazepine (CBZ) rice bran wax (RBW) microspheres adequate for the purpose of sustaining its release in case of long-term therapy which is highly essential in the treatment of epilepsy.

\section{MATERIALS AND METHODS}

Materials

CBZ sample was procured from Bajaj Private Ltd., Mumbai. Matruby Trades and Solutions Private Limited, Kochi, supplied the RBWs. Collagen was obtained from Nitta Gelatin Chemicals, Kochi. All other chemicals used were of analytical grade.
Preformulation studies

Preformulation studies are the first step in the rational development of dosage form of a drug substance.

\section{Identification of drug}

Solubility studies

Drug solubility studies were carried out in distilled water, ethanol, methyl alcohol, 1-propanol, acetone, 1-butanol, and in phosphate buffer pH 6.8.

Melting point determination

Melting point determination was carried out by capillary tube method [7].

\section{Compatibility studies of the drug CBZ with the excipients}

There should be an appreciable compatibility between the excipients and the drug for the formation of a stable formulation $[8,9]$.

\section{Fourier transform infrared spectroscopy (FTIR) studies}

The FT-IR spectra of the samples were obtained to ascertain the compatibility between CBZ and the selected polymers by FT-IR method [10].

\section{Formulation of CBZ microsphere (Table 1)}

To the melted RBW taken in a china dish, dispersed the drug CBZ (40 mg) into it and the melted mixture was added to $100 \mathrm{ml}$ distilled water at above $80^{\circ} \mathrm{C}$. Surfactant of concentration $1.8 \% \mathrm{w} / \mathrm{w}$ of Tween 
80 solution was poured into the mixture using a magnetic stirrer setted at $800 \mathrm{rpm}$ for not more than 15-20 minutes which was then cooled to room temperature, filtered and then washing has to be done so as to get spherical shaped microspheres after air drying [11]

\section{Characterization of microspheres}

Drug content analysis

This was carried out using appropriate dilutions of drug with methanol at a wavelength of $285 \mathrm{~nm}$ spectrophotometrically using methanol as blank.

\section{In vitro studies for drug release}

Apparatus of Type II USP paddle was used for this study, and it was done by a standardized procedure, which was then analyzed spectrophotometrically at $285.5 \mathrm{~nm} \mathrm{[12]}$

Formulation of collagen rectal hydrogel containing CBZ RBW microspheres (Table 2)

Before the experiment the required quantity of collagen was cooled to a temperature below $10^{\circ} \mathrm{C} .2 .5 \%$ of collagen was taken in a beaker and added $0.5 \mathrm{ml}$ of sodium hydroxide, $0.5 \mathrm{ml}$ of $\mathrm{pH} 6.8$ phosphate buffer and $1 \mathrm{ml}$ distilled water. These were mixed well. To this $1 \%$ of CBZ loaded RBW microspheres were added to obtain a gel of desired consistency. To this gel, two drops of glutaraldehyde were added and mixed.

\section{Characterization of collagen rectal hydrogel}

\section{Physicochemical properties}

Physicochemical evaluations such as pH measurement, homogeneity measurement, measurement of strength and consistency of hydrogels, spreadability, drug content, rheological studies, etc., were determined.

\section{Surface $p H$ measurement}

The $\mathrm{pH}$ values of the hydrogels were determined by dispersing $1 \mathrm{~g}$ of each formulated hydrogel in $30 \mathrm{ml}$ distilled water and recorded by a digital $\mathrm{pH}$ meter.

\section{Homogeneity measurement}

The hydrogels were visually inspected for general appearance and presence of any aggregates after they had been set in their final containers.

\section{Measurement of strength and consistency of hydrogels}

The gel strength was determined according to a method reported. A sample of $50 \mathrm{~g}$ of prepared hydrogel was placed in a $100 \mathrm{ml}$ graduated cylinder. A standard weight of $35 \mathrm{~g}$ was placed onto the hydrogel surface. The strength of gel was determined by measuring the time in seconds taken by the weight to penetrate $5 \mathrm{~cm}$ down through the gel. Arrange of 10-50 seconds was acceptable for rectal application. A timeless than 10 seconds was considered to cause gel leakage out from the rectum whereas more than 50 seconds would be too viscous for rectal administration [13].

\section{Spreadability}

Spreadability parameter of the freshly prepared hydrogels was evaluated by an accepted procedure of sliding it between two glass slides.

\section{Rheological studies}

The Brookfield apparatus for viscosity measurement was done using a standardized procedure. Rotations of the gel were carried out for 2 minutes in a spindle 7 and accordingly dial reading is recorded. A typical run should be carried out changing the speed from 10 to $100 \mathrm{rpm}$ at room temperature. For pseudoplastic flow, $\mathrm{n}>1$ while for dilatancy, $\mathrm{n}<1$

\section{In vitro mucoadhesion studies}

The mucoadhesive properties of hydrogels loaded with CBZ microspheres were carried out. The method was based on assessing the time required for detachment of the hydrogel spread on the bovine rectal mucosa. Sections of the bovine rectum tissues were surgically removed and placed in saline solution. The tissues were stored frozen in phosphate buffer pH 6.8 and thawed to room temperature before use. At the time of testing, a section of bovine rectum tissue was tied on a beaker. A known quantity of hydrogel (1 g) was placed onto the rectal mucosa. The beaker was filled with $100 \mathrm{ml}$ phosphate buffer $\mathrm{pH} 6.8$ at $37 \pm 0.5^{\circ} \mathrm{C}$ and magnetically stirred at $100 \mathrm{rpm}$. The time for complete erosion of the hydrogels from the rectal mucosal surface was determined visually and recorded as an indication of the in vitro adhesion time [14]

\section{In vitro drug release studies}

A modified method was adopted, where a known quantity of the hydrogel was introduced into the glass tube of $2.5 \mathrm{~cm}$ diameter and $3 \mathrm{~cm}$ length opened from both ends. The lower end of the tube was tightly covered with a dialysis membrane and the upper was hanged to the shaft of a USP Type II paddle apparatus dissolution rate rotating at rpm 100. The tubes were adjusted so that the dialysis membrane (Sigma-Aldrich) was below the surface of $100 \mathrm{ml} \mathrm{pH} 6.8$ phosphate buffer maintained in $37 \pm 0.5^{\circ} \mathrm{C}$ condition at $\mathrm{pH}$ in between $6.5-7.2$ range, imitating rectal fluid which is the desired medium for drug absorption. Aliquot samples were suitably diluted with phosphate buffer $\mathrm{pH} 6.8$ and

Table 1: Formulation composition of CBZ rice bran wax microspheres

\begin{tabular}{|c|c|c|c|c|c|c|c|c|c|c|}
\hline S. No. & Ingredients & $\mathbf{M}_{1}$ & $\mathbf{M}_{2}$ & $\mathbf{M}_{3}$ & $\mathbf{M}_{4}$ & $\mathbf{M}_{5}$ & $\mathbf{M}_{6}$ & $\mathbf{M}_{7}$ & $\mathbf{M}_{8}$ & $\mathbf{M}_{9}$ \\
\hline 1 & RBW (g) & 4 & 8 & 12 & 4 & 8 & 12 & 4 & 8 & 12 \\
\hline 2 & CBZ (mg) & 30 & 30 & 30 & 40 & 40 & 40 & 50 & 50 & 50 \\
\hline 3 & CBZ: RBW(\%w/w) & 133 & 266 & 400 & 100 & 200 & 300 & 80 & 160 & 240 \\
\hline 4 & Tween $80(\%)$ & 1.8 & 1.8 & 1.8 & 1.8 & 1.8 & 1.8 & 1.8 & 1.8 & 1.8 \\
\hline 5 & Distilled water $(\mathrm{ml})$ & 150 & 150 & 150 & 150 & 150 & 150 & 150 & 150 & 150 \\
\hline
\end{tabular}

RBW: Rice bran wax, CBZ: Carbamazepine

Table 2: Formulation composition of collagen rectal hydrogel containing CBZ loaded RBW microspheres

\begin{tabular}{|c|c|c|c|c|c|c|c|}
\hline S. No. & Ingredients & H1 & H2 & H3 & H4 & H5 & H6 \\
\hline 1 & $\begin{array}{l}\text { CBZ loaded RBW microspheres -M5 } \\
\text { optimized formulation (\%) }\end{array}$ & 1 & 1 & 1 & 1 & 1 & 1 \\
\hline 2 & Collagen $(\%)$ & 10 & 15 & 20 & 25 & 30 & 35 \\
\hline 3 & Phosphate buffer pH 6.8 (ml) & 0.5 & 0.5 & 0.5 & 0.5 & 0.5 & 0.5 \\
\hline 4 & Glutaraldehyde (drops) & 2 & 2 & 2 & 2 & 2 & 2 \\
\hline 5 & Sodium hydroxide $0.1 \mathrm{~N}(\mathrm{ml})$ & 0.5 & 0.5 & 0.5 & 0.5 & 0.5 & 0.5 \\
\hline 6 & Distilled water $(\mathrm{ml})$ & 10 & 10 & 10 & 10 & 10 & 10 \\
\hline
\end{tabular}


analyzes spectrophotometrically in $285.5 \mathrm{~nm}$. All experiments were carried out in triplicates and the mean values were presented [15]

\section{Ex vivo permeation studies}

This study was carried out in a specialized apparatus called the Franz diffusion cell having capacity of approximately $15 \mathrm{ml}$ for receptor compartment by accepted procedure. A comparison study was done between optimized H4 hydrogel formulation, CBZ API loaded hydrogel (without microsphere) formulation, drug in phosphate buffer pH6.8 solution, etc. [16,17]

\section{Scanning electron microscopy (SEM)}

The optimized hydrogel formulation (H5) were diluted with distilled water and examined with the SEM.

\section{Histopathological examination}

The pretreated mucosa which was subjected to the in vitro permeation was examined for any changes after accepted procedure [18].

\section{Stability studies}

The H4 rectal hydrogel was undergone stability evaluation for 60 days in refrigerated $\left(4 \pm 2^{\circ} \mathrm{C}\right)$ and room temperature $\left(30 \pm 2^{\circ} \mathrm{C}\right)$ condition and analyze for drug content [19-21].

\section{RESULTS AND DISCUSSIONS}

\section{Solubility studies}

The pure drug is partially soluble in water and ethanol and completely soluble in methanol, phosphate buffer pH 6.8.

\section{Melting point of the drug}

The result of M.P determination was in the range of $189^{\circ} \mathrm{C}-193^{\circ} \mathrm{C}$.

\section{FTIR studies}

FTIR spectrum of CBZ, drug+RBW, plain RBW microspheres, collagen, physical mixture of drug with collagen and CBZ-RBW microspheres loaded collagen hydrogel formulations were shown in Fig. 1.

- FTIR spectra of CBZ showed characteristic absorption bands at $3467 / \mathrm{cm}\left(\mathrm{NH}\right.$ stretching of $\mathrm{NH}_{2}$ ), 3080/cmaromaticity (aromatic $\mathrm{CH}$ stretching), $1678 / \mathrm{cm}\left(\mathrm{C}=0\right.$ stretching of $\left.\mathrm{CO} \mathrm{NH}_{2}\right), 1605$, $1489 / \mathrm{cm}(\mathrm{C}=\mathrm{C}$ ring stretching) showed strong peak at 3029/ cmindicating the presence of $-\mathrm{OH}$ group.

- $\quad$ FTIR spectra of collagen showed strong peak at $1650 / \mathrm{cm}$ indicating the presence of amide I carbonyl stretching region, amide II at $\sim 1560 / \mathrm{cm}$, and a set of three weaker bands that represent amide III vibration modes centered at $\sim 1245 / \mathrm{cm}$

- $\quad$ FTIR peaks for RBW are at $2917-2852 / \mathrm{cm}$, minor peaks at 1730 , 1497,1461 , and $1377 / \mathrm{cm}$.

- The drug loaded hydrogel formulation exhibit a spectrum from 3500 to $3300 / \mathrm{cm}$ indicating the presence of amine group. $3083 / \mathrm{cm}$ (aromatic CH stretching), 1678/cm (C=O stretching of $\mathrm{CO} \mathrm{NH}_{2}$ ), showed strong peak at $3029.73 / \mathrm{cm}$ indicating the presence of $-\mathrm{OH}$ group.

- Absence of extra peaks indicates good compatibility between drug and the excipients.

Formulation of CBZ loaded RBW microspheres by modified cooling induced solidification method

The preparation strongly urges the need of optimization of certain parameters such as concentration of wax, speed rate of stirring, concentration of surfactant, and temperature. Optimum $\mathrm{pH}$ for maximum drug loading was found to be 6.8 with distilled water as the external phase. Tween 80 concentration was optimized to $1.8 \% \mathrm{w} / \mathrm{w}$.

\section{Drug content analysis}

The drug content analysis was carried out for all prepared microsphere formulations. The drug content of all formulation ranged between $57.23 \pm 0.14 \%$ to $92.33 \pm 0.36 \%$ as mentioned in Table 3 and Fig. 2. The maximum drug content was found to be $92.33 \pm 0.36 \%$ for microsphere formulation M5. Drug content in the formulation depends on the concentration of polymer in microsphere. Drug content increases with increase in polymer concentration. However, the pharmaceutically applicable drug loading was found to be maximum when the drug to polymer ratio was taken as 1:200\% w/w.

\section{IN VITRO RELEASE STUDIES OF DRUG}

The release studies of drug loaded microsphere formulations were carried out for $12 \mathrm{hr}$ (Fig. 3). 6.8 phosphate buffer was selected as the simulated rectal fluid which is the desired medium for drug absorption. The $\mathrm{pH}$ was maintained constant for the entire study duration using USP Type II Paddle dissolution apparatus. Maximum release was obtained for M5 and M8 formulations which are $97.48 \pm 1.98 \%$ and $84.78 \pm 0.23 \%$, respectively. The release of the drug from the formulation depends on the concentration of polymer, but if the concentration of the polymer is excessively increased release of

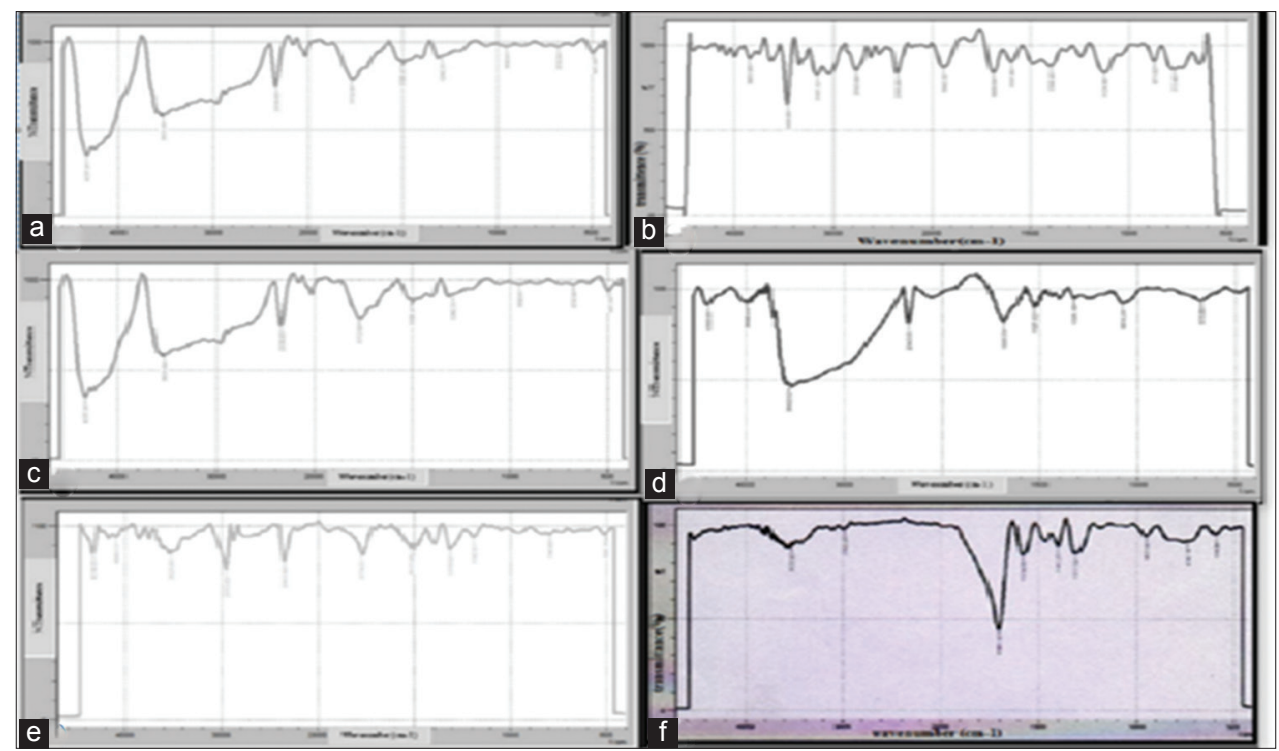

Fig. 1: (a) Fourier transform infrared spectroscopy (FTIR) of carbamazepine (CBZ), (b) FTIR spectrum of CBZ+rice bran wax, (c) FTIR spectrum of plain rice bran wax microspheres, (d) FTIR spectrum of collagen, (e) FTIR spectrum of drug+collagen, and (f) FTIR spectrum of CBZ rice bran wax microsphere loaded hydroge 
the drug gets affected. The optimized formulation was found to be M5 which exhibits highest percentage of release in a controlled manner for $12 \mathrm{hr}$. This controlled release with high percentage of release was due to optimized drug to wax ratio. M5 formulation contains $1 \% \mathrm{w} / \mathrm{w}$ of drug and drug to polymer ratio of 1:200. Further, optimized formulation M5 was selected for the formulation of collagen rectal hydrogel [22].

Formulation of collagen rectal hydrogel containing CBZ RBW microspheres

\section{Preparation of collagen hydrogel}

Hydrogels were prepared using 1\% w/w of optimized M5 microspheres. Here, the polymer used was collagen which is a natural one. It is an abundant structural protein in all animals. Collagen is selected as the polymer because of the following properties:

- Thickening agent

- Mucoadhesion property

- Tissue compatibility

Table 3: Determination of percentage drug content

\begin{tabular}{ll}
\hline Formulation & Drug content (\%) \\
\hline M1 & $57.23 \pm 0.14$ \\
M2 & $69.34 \pm 0.34$ \\
M3 & $65.36 \pm 1.93$ \\
M4 & $59.65 \pm 0.36$ \\
M5 & $92.33 \pm 0.43$ \\
M6 & $72.82 \pm 0.56$ \\
M7 & $63.56 \pm 0.98$ \\
M8 & $83.45 \pm 0.45$ \\
M9 & $76.38 \pm 1.76$ \\
\hline
\end{tabular}

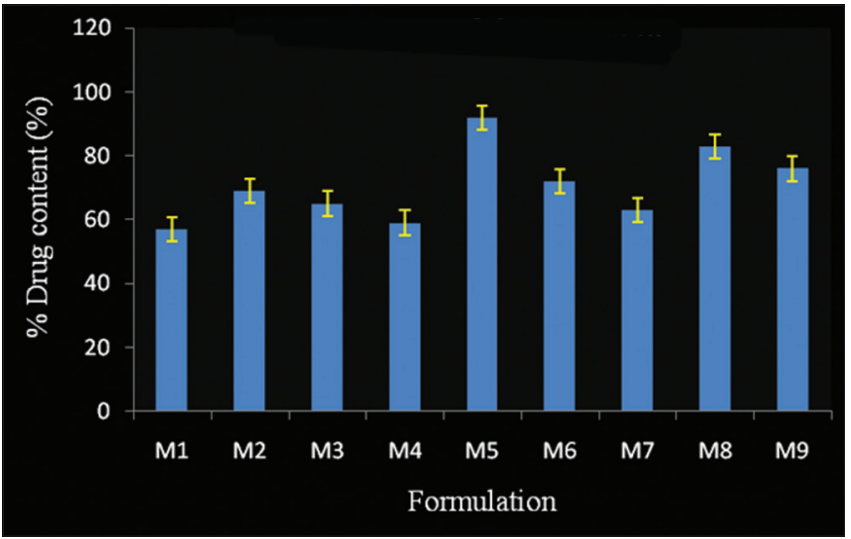

Fig. 2: Determination of percentage drug content

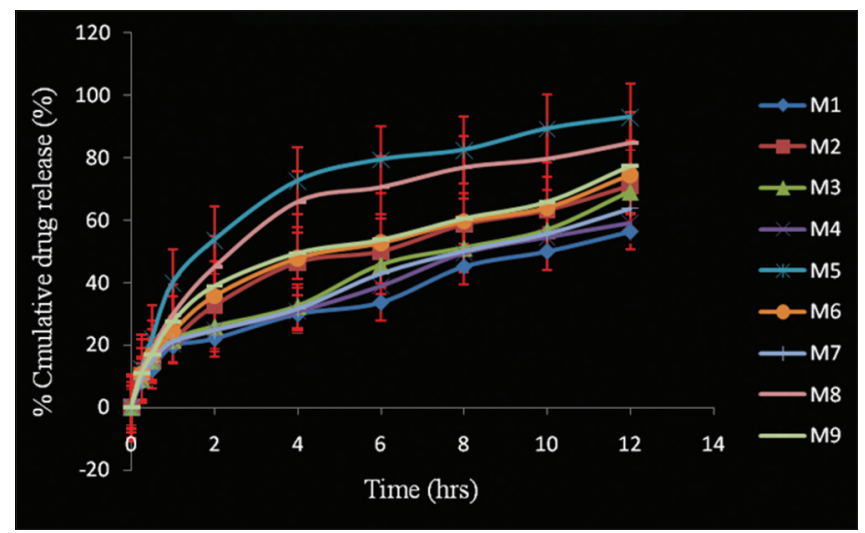

Fig. 3: In vitro release of carbamazepine loaded rice bran wax microspheres
- $\quad$ Biodegradability

- Viscosity enhancement property.

For the formulation of the hydrogel, collagen must be cooled to a temperature before the experiment. This is mandatory to obtain gel of desired consistency. The formulation was performed by varying the percentage of collagen between $10-35 \% \mathrm{w} / \mathrm{w}$. According to the change in collagen concentration, a total of six formulations from $\mathrm{H} 1$ to $\mathrm{H} 6$ were prepared. The polymer must be added slowly to distilled water with constant stirring so that the formation of lumps could be avoided. The optimum amount of distilled water used was $10 \mathrm{ml}$. If the amount of distilled water was increased, the desired gel consistency could not be achieved. Sodium hydroxide $(0.1 \mathrm{~N})$ was added to adjust the $\mathrm{pH} .1 \%$ of the optimized microsphere M5 formulation is incorporated to hydrogel after wetting it with $0.5 \mathrm{ml}$ of phosphate buffer of $\mathrm{pH}$ 6.8. This wetting step was performed to enhance the distribution of microspheres. After the wetting process, the microspheres were uniformly distributed into the structured vehicle of hydrogels by gentle mixing with a mechanical stirrer. Glutaraldehyde is added as the cross linking agent to sustain the drug release and was again mixed until gel was formed, so the final concentration of CBZ in hydrogels was $1 \%$ w/w, shown in Fig. 4.

\section{Characterization of collagen rectal hydrogel \\ Surface $p H$ measurement}

The formulated hydrogels had $\mathrm{pH}$ values in range of 6.5-7.4, which were close to the rectal $\mathrm{pH}$ of 6.8 . Hence, these values indicated the suitability of the hydrogels for rectal application with minimal risk of tissue irritation.

\section{Homogeneity measurement}

All the formulated hydrogels showed good homogeneity with the absence of lumps, indicates uniform distribution of drug within the formulation.

\section{Measurement of strength and consistency of hydrogels}

The strengths of collagen hydrogels $\mathrm{H} 1-\mathrm{H} 4$ were within the acceptable range (10-50 s). The $\mathrm{H} 5$ and $\mathrm{H} 6$ formulations showed a higher strength reaching 59.32 and 63.4 seconds, respectively. These values clearly revealed that the strength of collagen hydrogels could not be considered suitable for rectal application (Fig. 5).

\section{Spreadability}

The formulated hydrogels exhibited satisfactory spreadability which points to equality to application of drug. The spreadability of the optimized hydrogel formulation $\mathrm{H} 4$ was in the range of $25.48 \pm 2.78 \mathrm{~g} \mathrm{~cm} /$ seconds.

Drug content analysis

For any formulation there should be uniformity in drug distribution, hence the desired therapeutic concentration will be reached to the specific site. This will give a clear indication of its action in the body. All the formulations exhibited fairly appreciable drug content. Simple and less complicated procedure will account minimum chance of drug, i.e., addition of $1 \%$ of optimized formulation of drug bearing microsphere (M5) to the polymer solution. The drug content was observed in the range of $88.73 \pm 0.45 \%$ to $97.48 \pm 0.62 \%$ (Fig. 6). The optimized formulation $\mathrm{H} 4$ containing $25 \%$ of collagen showed maximum drug content.

\section{Rheological studies}

H1-H4 formulations were suitable for rheological studies after taking viscosity measurements shown in Fig. 7.

\section{In vitro mucoadhesion studies}

Fig. 8 presented the bioadhesion time taken by hydrogel formulae to erode from the rectal mucosal tissue. It was observed that $\mathrm{H} 4$ hydrogel 


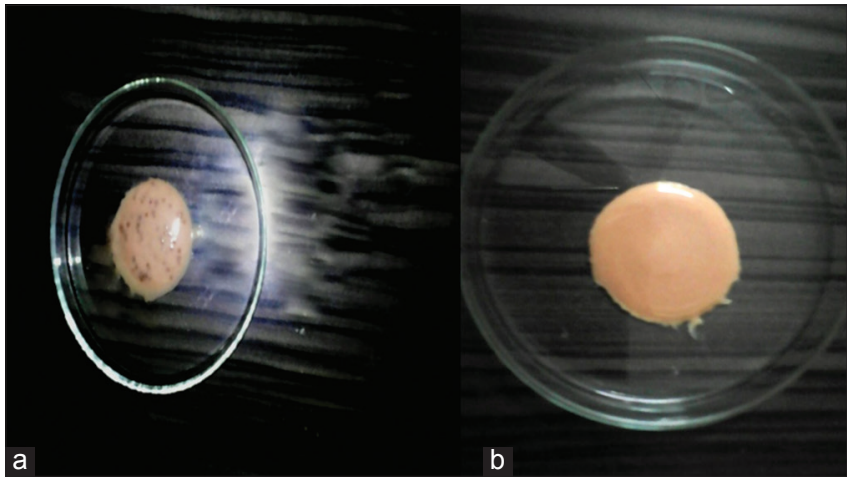

Fig. 4: (a) Carbamazepine rice bran wax microsphere loaded collagen hydrogel. (b) Carbamazepine API loaded collagen hydrogel

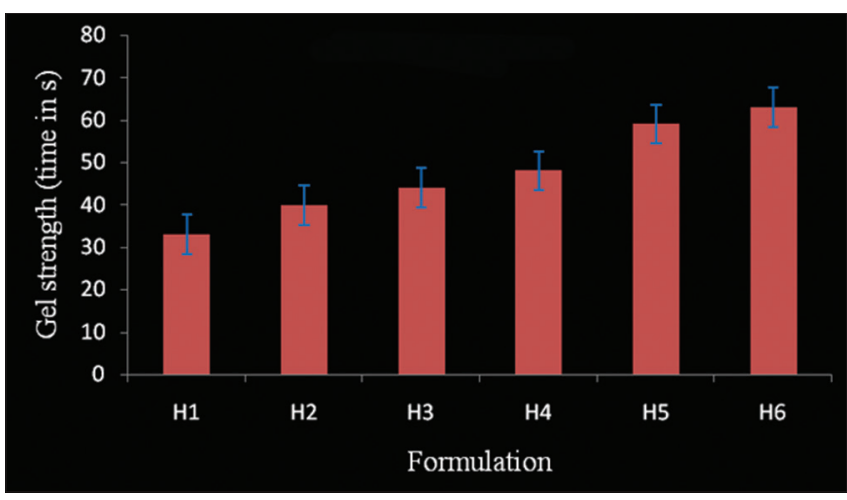

Fig. 5: Gel strength

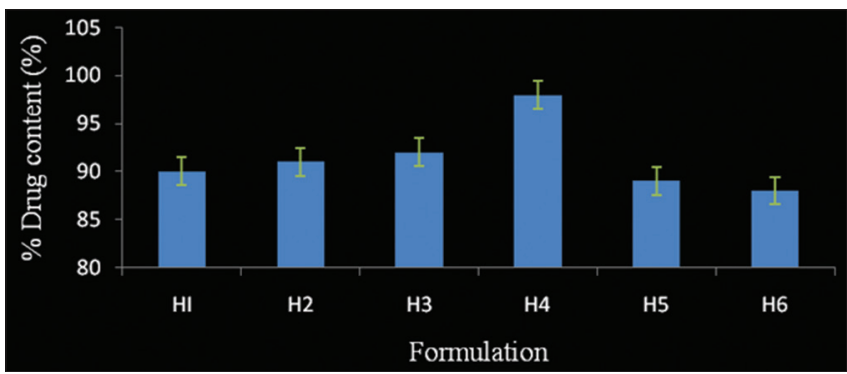

Fig. 6: Drug content of different hydrogel formulations

formulation had the highest in vitro adhesion time (565 minutes), whereas the adhesion time of other hydrogels was comparatively lesser. Collagen is a good mucoadhesive agent. The polymer concentration and bioadhesion time had a linear proportionality relationship. Furthermore, the mucoadhesion time will be greater up to collagen concentration of $25 \%$ and further increase in collagen concentration showed decreased bioadhesion. The high residence time shown by the prepared rectal hydrogels gave a chance to the loaded microspheres to be attached to the mucosal surface and slowly elute the drug providing a controlled effect.

\section{In vitro drug release studies}

The study was conducted for duration of $12 \mathrm{hrs}$ and release percentage from 0 to $12 \mathrm{hrs}$ was taken. From $\mathrm{H} 1-\mathrm{H} 4$, the percentage value of release of drug value was considerably increased and dropped subsequently for $\mathrm{H} 5$ and $\mathrm{H} 6$ formulation. Maximum release was obtained for $\mathrm{H} 4$ formulation with $96.45 \pm 0.35 \%$ than other formulations shown in Fig. 9 . Equal amount of drug loaded microspheres were used to formulate all six hydrogel formulations, but the \% of polymer (collagen) used varies. These hydrogels act as a reservoir which release the drug at

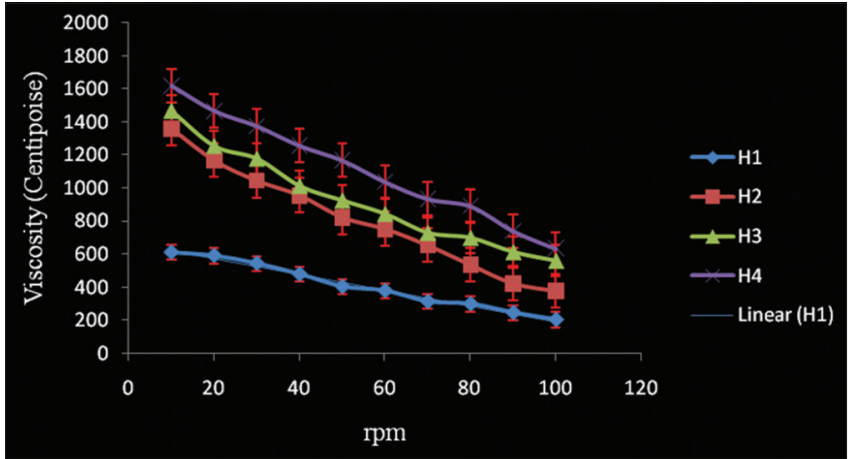

Fig. 7: Rheological properties of selected hydrogel formulations

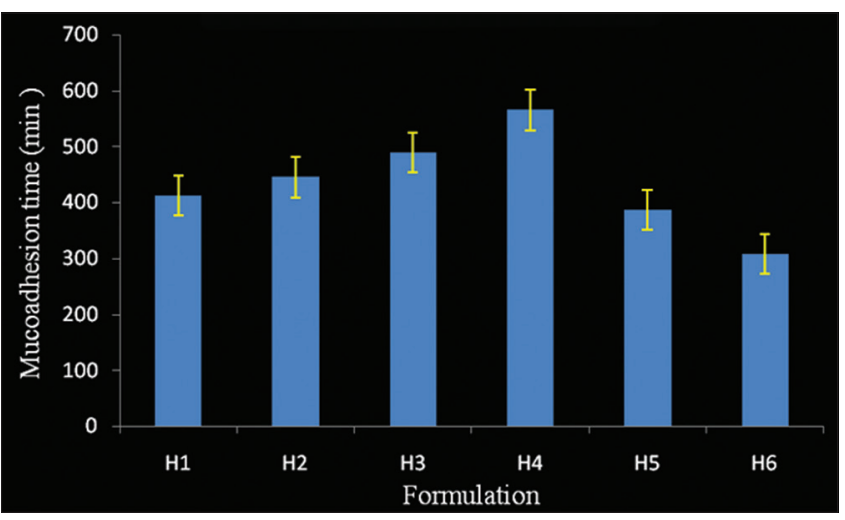

Fig. 8: Comparison of mucoadhesion time of different formulations

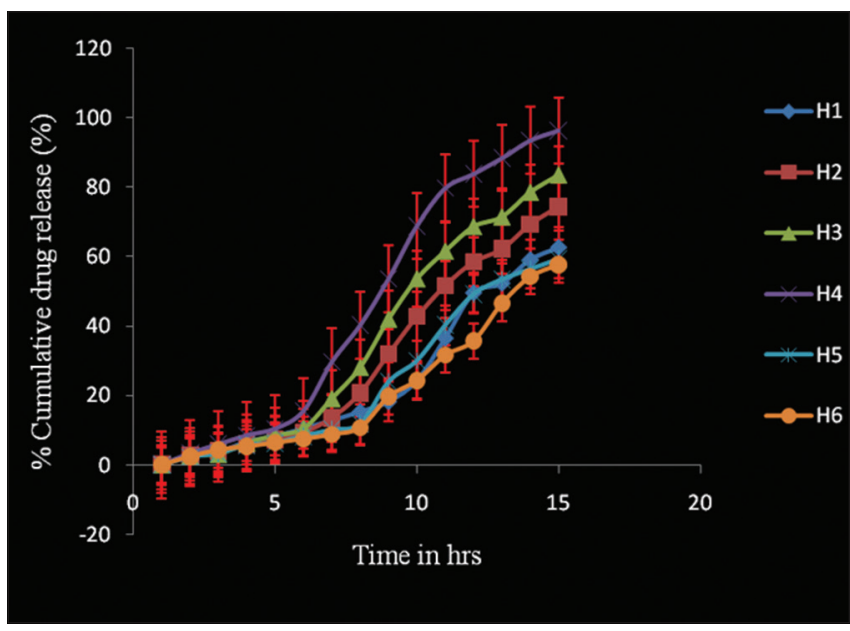

Fig. 9: In vitro drug release of different formulations of carbamazepine rice bran wax microsphere loaded hydrogel formulations

a minimum pace, in a sustained manner at a considerable duration. ${ }^{50} \mathrm{H} 4$ formulation contains $25 \%$ collagen which could be concluded as the optimum collagen concentration to exhibit maximum percentage release. Further increment in polymer \% showed a fall in percentage release ( $\mathrm{H} 5$ and $\mathrm{H} 6$ formulations).Kinetic studies were also performed.

\section{Ex vivo permeation studies}

The rectal mucosa represents a layer with high vascularization. The bovine rectal mucosa was selected because of its physiological resemblance to human rectal mucosa and the studies were conducted in Franz diffusion cell. The ex vivo permeation study gives a clear idea about the behavior of the moiety in vivo. There is proportionality 


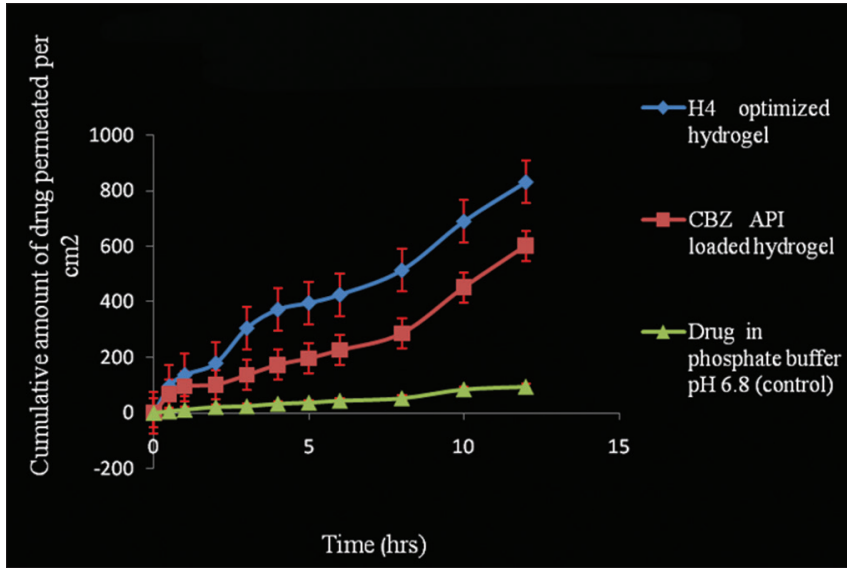

Fig. 10: EX vivo permeation comparison studies of selected formulations with control

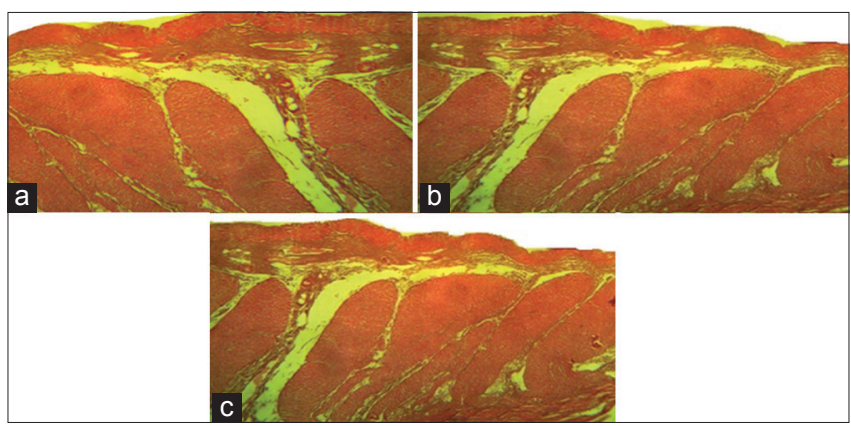

Fig. 11: (a-c) Histopathological evaluation

between the quantity of drug permeated and the quantity of drug absorbed. A comparison study was done between optimized $\mathrm{H} 4$ hydrogel formulation, CBZ API hydrogel (without microsphere) formulation, drug in phosphate buffer $\mathrm{pH} 6.8$ solution, etc. The ex vivo permeation studies were performed only for $12 \mathrm{hrs}$ as the rectal mucosa undergoes degradation when it was kept for longer period which was indicated by foul smell. The ex vivo permeation studies as seen in Fig. 10 confirmed that the optimized formulation $\mathrm{H} 4$ shows maximum permeation.

\section{Histopathological examination}

As shown in Fig. 11, histopathological study of the rectal mucosa after permeation study suggested that the optimized hydrogel $\mathrm{H} 4$ formulation was safe for rectal administration.

\section{SEM}

The discrete and spherical shaped with a rough outer surface and visible wrinkles are shown in SEM studies (Fig. 12).

\section{Stability studies}

From the stability studies (Fig. 13) the optimized H4 hydrogel formulation, it was confirmed that $\mathrm{H} 4$ formulation was stable at two different conditions.

\section{CONCLUSION}

A number of delivery systems have been investigated for use in neurological disorders like epilepsy, but still a novel delivery system to combat this incurable firing disorder is yet to be developed. Antiepileptic medications are used as first line treatment option but conventional therapy is accompanied by a handful of side effects. Rectal route offers a noninvasive useful route of drug administration when systemic or local effects are requested. Rectal administration is of now widely employed which could be as effective as the intravenous route. Furthermore nonmedical personnel, irrespective of the patient's ability to cooperate can administer rectal formulations easily and

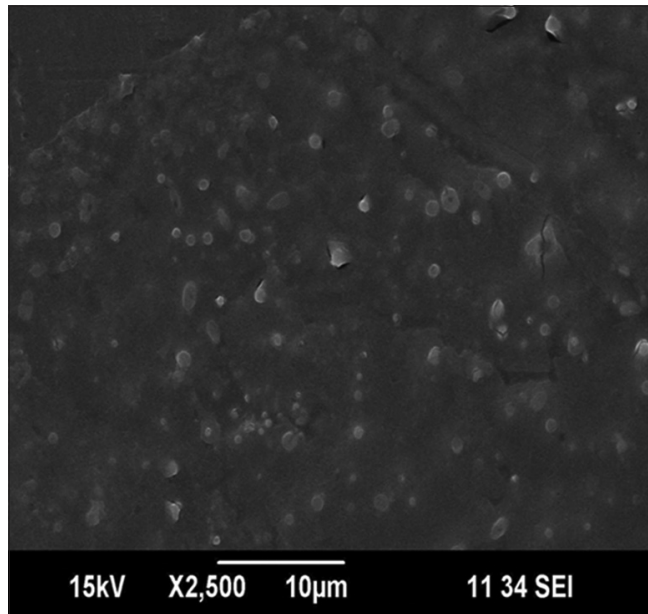

Fig. 12: Scanning electron microscopy of carbamazepine rice bran wax microsphere loaded hydrogel ( $\mathrm{H} 4$ formulation)

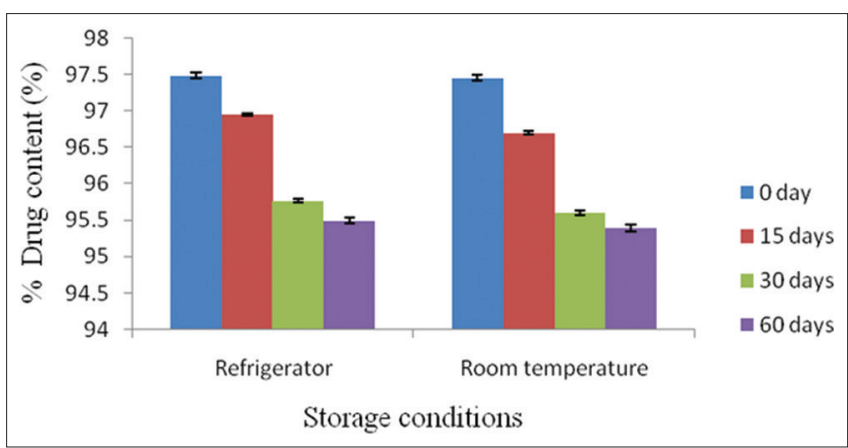

Fig. 13: Stability study of optimized rectal hydrogel (H4)

safely. Hydrogels are highly nonirritant and tissue compatible due to its excessive moisture content and resemblance to the natural cell environment. Collagen hydrogels containing CBZ RBW microspheres have been prepared and evaluated. The formula of $25 \%$ collagen loaded with CBZ RBW microspheres (H4 formulation) showed adequate rheological, mucoadhesive, and permeability properties. The suggested formula allowed the adhesion of hydrogel loaded with the drug CBZ to the rectal mucosa for subsequent sustained release behavior with no burst effect, which is a major disadvantage of CBZ immediate release systems. In vitro release kinetics of formulation clearly indicated that the CBZ microsphere loaded hydrogels exhibited zero order release following Higuchi model as the diffusion mechanism. Histopathological examination demonstrated that the optimized $\mathrm{H} 4$ hydrogel formulation produce neither mucosal remodeling nor rectal irritancy and hence evaluated to be safe for rectal administration. The main purpose of this work which was to formulate a rectal hydrogel with sustained release of drug so as to minimize drug related adverse effects and frequency of dosage was successfully attained.

\section{REFERENCES}

1. Wallace H, Shorvon S, Tallis R. Age-specific incidence and prevalence rates of treated epilepsy in an unselected population of 2,052,922 and age-specific fertility rates of women with epilepsy. Lancet 1998;352(9145):1970-3

2. Engelborghs S, D'Hooge R, De Deyn PP. Pathophysiology of epilepsy. Acta Neurol Belg 2000;100(4):201-13

3. Ramesh K, Krishnapriya M, Anupriya, Nair SC. An outlook to nonpharmacological and novel approaches to combat the uncurable firing disorder. Int J Pharm Sci Rev Res 2016;40(1):55-61.

4. Nair SC, Anoop KR. Local antimicrobial delivery of satranidazole loaded cross linked periodontal chips using bio degradable polymers. Int J Pharm Pharm Sci 2013;5(3):839-47.

5. Prasanth VV, Moy AC, Mathew ST, Mathapan R. Microspheres-an 
overview. Int J Pharm Biomed Sci 2011;2(2):332-8.

6. Vashist A, Ahmad S. Hydrogels: Smart materials for drug delivery. Orient J Chem 2013;29(3):861-70.

7. Cloyd JC, Lalonde RL, Beniak TE, Novack GD. A single-blind, crossover comparison of the pharmacokinetics and cognitive effects of a new diazepam rectal gel with intravenous diazepam. Epilepsia 1998;39(5):520-6.

8. Sahil K, Akanksha M, Premjeet S, Bilandi A, Kapoor B. Microsphere: A review. Int J Res Pharm Chem 2011;1(4):1184-98.

9. Saboktakin MR, Tabatabaie RM, Maharramov A, Ramazanov MA. Synthesis and characterization of biodegradable chitosan beads as nano-carriers for local delivery of satranidazole. Carbohydr Polym 2010;81(3):726-31.

10. Jain SK, Jain A, Gupta Y, Ahirwar M. Design and development of hydrogel beads for targeted drug delivery to the colon. AAPS PharmSciTech 2007;8(3):E56.

11. Fahim F, Naseer A, Ahmed S, Sherazi ST, Bhanger MI. A green approach for the determination of selected anti-diabetic drugs in pharmaceutical formulation by transmission FTIR spectroscopy. J Braz Chem Soc 2014;25(11):2032-8

12. Ishaka A, Umar Imam M, Mahamud R, Zuki AB, Maznah I. Characterization of rice bran wax policosanol and its nanoemulsion formulation. Int J Nanomedicine 2014;9:2261-9.

13. Ibrahim MM, Sammour OA, Hammad MA, Megrab NA. In vitro evaluation of proniosomes as a drug carrier for flurbiprofen. AAPS PharmSciTech 2008;9(3):782-90.

14. Choi HG, Jung JH, Ryu JM, Yoon SJ, Oh YK, Kim CK. Development of in situ-gelling and mucoadhesive acetaminophen liquid suppository. Int J Pharm 1998;165(1):33-44s

15. El-Samaligy MS, Yahia SA, Basalious EB. Formulation and evaluation of diclofenac sodium buccoadhesive discs. Int J Pharm 2004;286(1-2):27-39.

16. El-Hady SA, Mortada ND, Awad GA, Zaki NM, Taha RA. Development of in situ gelling and mucoadhesive mebeverine hydrochloride solution for rectal administration. Saudi Pharm J 2003;11(4):159-71.

17. Dragicevic-Curic N, Scheglmann D, Albrecht V, Fahr A. Temoporfinloaded invasomes: Development, characterization and in vitro skin penetration studies. J Control Release 2008;127(1):59-69.

18. El-Leithy ES, Shaker DS, Ghorab MK, Abdel-Rashid RS. Evaluation of mucoadhesive hydrogels loaded with diclofenac sodium-chitosan microspheres for rectal administration. AAPS PharmSciTech 2010;11(4):1695-702.

19. Shivhareu D, Tijare PM. Formulationand characterization of microspheres of selected anti-infective agent for urinary tract infection. J Drug Dev Res 2013;2(1):16-26.

20. John MS, Nair SC, Anoop KR. Thermoreversible mucoadhesive gel for nasal delivery of anti hypertensive drug. Int J Pharm Sci Rev Res 2013;21(1):57-63.

21. Nair RV, Nair SC. Cross linked chitosan in situ gel of satranidazole for intra periodontal drug delivery. Int Res J Pharm 2014;5(4):239-43.

22. Nair AS, Vidhya KM, Saranya TR, Sreelakshmy KR, Nair SC. Mucoadhesive buccal patch of cefixime trihydrate using biodegradable natural polymer. Int J Pharm Pharm Sci 2014;6(6):366-71 